\title{
Research on Practical Teaching Recording System Based on QuickTime Virtual Reality Technology
}

\author{
http://dx.doi.org/10.3991/ijoe.v9i5.2606 \\ Yongyong Zhu \\ Southwest University of Political Science and Law, Chongqing, China \\ Chongqing University of Education, Chongqing, China
}

\begin{abstract}
QuickTime Virtual Reality Technology (QTVR) is virtual reality technology which is based on static images. Through the practical teaching record system, virtual reality technology is applied to the whole journey of practical teaching. We apply QTVR to practical teaching section and give full play to the merits of strong sense of reality of the QTVR technology, good interactive performance, impressive immersive experience, convenience of produce and transmission, make seamless integration with the various present online teaching platforms, constitute comprehensive teaching material accumulation and resource utilization, uplift the quality of practical teaching, and promote students' practical skills.
\end{abstract}

Index Terms-QuickTime Virtual Reality, Practical teaching, Recording and broadcasting system, Virtual reality technology.

\section{INTRODUCTION}

In the modern teaching practice, the recording and broadcasting system is something new in the practical teaching activities [1]. Practical teaching at this stage due to the presence of lots of experimental forms and experimental contents and experimental requirements, has a very high requirements on the experimental equipment, experimental materials, experimental site. While the current condition of a variety of software and hardware in different schools still can't meet the requirements of practical teaching. In the same time, the external support conditions of practical teaching constrained and influenced the carrying out of practical teaching and the students' practical ability to innovate to a certain extent [2]. To apply the QTVR virtual reality technology to the practical teaching and broadcasting system is a useful complement to the traditional practical teaching, which can not only save a lot of funding for education, but also can significantly extent the time and space in practical teaching so as to create a benefit condition for the development of information technology and the implementation of the broadcast system in the practical teaching process.

\section{VIRTUAL REALITY TECHNOLOGY}

Virtual reality, also known as immersive technology, produces a three-dimensional virtual world by utilizing computer modeling so as to provide users with visual, auditory, tactile and other sensory simulation to let users as immersive as to truly feet it, this technology has no limitation but to timely observe the three-dimensional things [3]. Virtual reality as a comprehensive integrated technology, mainly related to computer graphics, humancomputer interaction technology, sensor technology, artificial intelligence and other fields [4]. This technology integrates the computer graphics technology, computer simulation technology, artificial intelligence, sensor technology, the latest developments in display technology, network parallel processing technology, and high-tech simulation system, which is generated by the computer technical assistance. Virtual reality includes all natural simulation and realistic experience technology and methods, and their goal is a real experience and convenient and natural human-computer interaction, to achieve or part of the system to achieve such a goal is called virtual reality system [5].

Virtual reality, as a technology which integrate the highly realistic human-computer interaction technologies in the aspect of visual, auditory, tactile and visual behaviors, takes full advantage of the techniques and methods related to human's perception ability and maneuver ability [6]. As virtual reality technology has the characteristics of immersion, interaction, ideas, actions and autonomy, when a user as a protagonist participates in this simulated environment, the computer simulation environment allows users to feel sounds, move, smell and taste like in the real world, etc. Everything seems to be true, the user feel natural objects within the simulation environment actionable level and get feedback from the environment as the real world. Therefore, virtual reality technology by virtue of its low cost, the method is simple, easy to use and the advantages of an easy solution to the problems previously required complicated and expensive specialized equipment to show the real-life scenarios [7].

With the development of the computer, as well as means of human-computer interaction, virtual reality technology in the teaching process is mainly used in virtual labs, virtual classroom, virtual library, virtual campus, virtual studio, virtual remote education, virtual reality system also includes desktop type, photometric, immersion and network distributed virtual reality system, and so on [8]. Virtual reality technology is gradually changing the traditional mode of education, supervision and teaching passive learning mode into learners through their own information environment interaction to obtain the knowledge, skills, active learning mode. 


\section{QUICKTIME VIRTUAL REALITY}

QTVR is based on "QuickTime Virtual Reality", the abbreviation, the expansion of U.S. Apple Quick Time technology, is a static image processing can be achieved on the PC platform virtual reality technology. Kind of virtual reality, QTVR belongs to the desktop is the primary virtual reality technology, but shows its characteristics and advantages, so the popularity of the application of virtual reality technology has broad prospects [9]. QTVR does not require special hardware required by traditional virtual reality technology and ancillary equipment. An ordinary PC or Macintosh machine can produce a virtual reality experience. User interactive control by mouse, keyboard and other image acquisition system observing certain observation points around the 360-degree panoramic image, and then processing through QTVR systems software discrete image, to complete the three-dimensional space, the shape of three-dimensional objects. The emerging of QTVR technologies made all these VR experience on the PC can be realized. The emerging of QTVR technologies made all these VR experience on the PC can be realized. With the in-depth research and development of QTVR technology, its applications in the field of education will be further deepen and broaden in this process [10].

Based on the principle of the three-dimensional shape, QTVR is an image-based 3D modeling and dynamic display technology which has basic functionalities such as sight switch, sliding lens, hypermedia links and other characteristics. From the perspective of performance, QTVR is able to achieve a considerable degree of virtual reality experience in an ordinary $\mathrm{PC}$ or Macintosh machine [11]. QTVR has a realistic, interactive performance, strong sense of immersion and easy to generate, transmit, reality scene acquisition, processing and rendering, image mosaic complex environment, realtime modeling and dynamic displays, fast generate the desired scene, giving viewers an immersion $3 \mathrm{D}$ real. QTVR with features and interactive features to allow the students to experience a different time and space in the simulation process, contact with a variety of simulation objects, contact with various parts of the virtual realm, accelerate and consolidate the process of student learning knowledge. Compared with the traditional teaching of CAI, QTVR performs better in picture quality and more beautifully in use of color, making the process simpler, and making the more operation user-friendly. The application of the QTVR technology in the field of education can promote the changes in teaching concept, teaching content and teaching spaces changes and can save the investment in education and improve teaching effectiveness, which is conducive to the cultivation of students' innovative spirit, innovation and collaboration awareness [12].

\section{QUickTime Virtual REALITY TECHNOLOGY Applies to Practical TEACHING RECORding System}

\section{A. Application flowchart of QTVR technology in practical teaching recording system}

We will apply the QTVR virtual reality technology in the recording and broadcasting system for practical teaching, throughout the recording and broadcasting system entire process of school practical teaching [13].
The process of practical teaching, arranged in accordance with the teaching plan, teaching design and lesson planning, classroom practical teaching, the process the process of recording and broadcasting system ready taped the curriculum editing, recording and broadcasting courses publishing process, in accordance with the recording of practical teaching courses release process, in accordance with the recording and broadcasting of information feedback, and modify the contents of the pre-recorded messages, modify the process of recording and broadcasting information to modify the way the recording and broadcasting system, in accordance with the student electronic notebook, online active learning, online Q \& A teaching demonstration network remote control, network remote hosting and other rich and broadcasting system effects, application flowchart of QTVR technology in practical teaching recording system, see figure 1 .

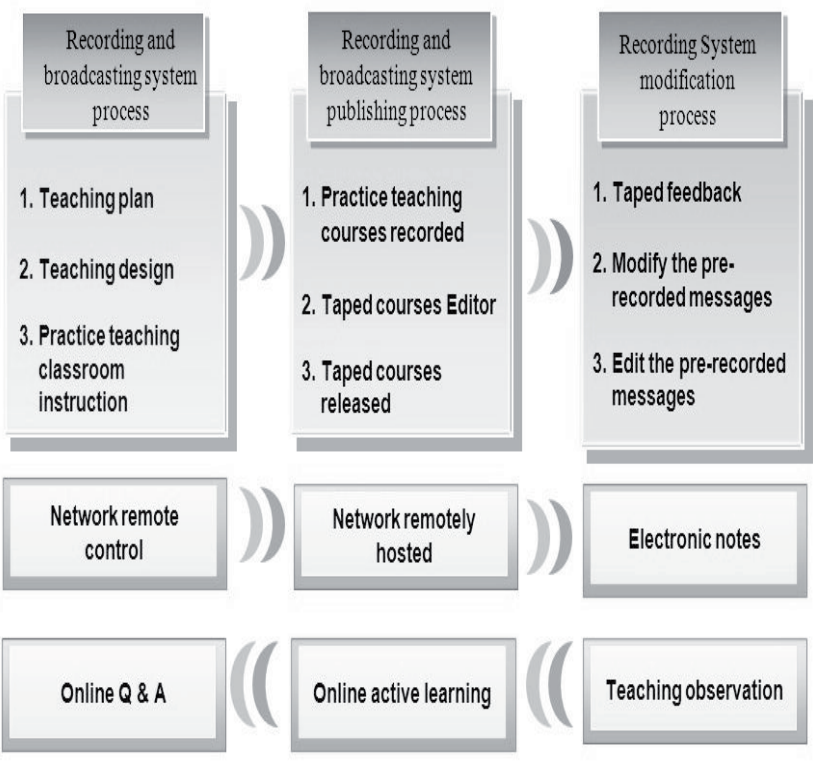

Figure 1. Application flowchart of QTVR technology in practical teaching recording system

The process of using QTVR virtual reality technology used in the practical teaching and broadcasting system together with the automatic recording and broadcasting system and course management platform system. The integrated use of software technologies for the intelligent, automatic, convenient knowledge system construction of practical teaching can release the teacher from the heavy, machinery, repeat physical labors of lesson planning and lecturing so as to make them get more time and effort for knowledge creation and update [14]. For students, they can give full play to learn by themselves, according to their own needs to choose the way of learning time and learning, the use of targeted learning software has taped practical teaching process, students enjoy teacher quality courses At the same time, enhance the quality of practical teaching to improve students' practical skills.

\section{B. QTVR technology apply into practical teaching Recording System}

QTVR virtual reality technology into practical teaching and broadcasting system principle is to rely on the cameras capture the video signal, the mixer collection audio signal recording and broadcasting machine data compressed output, and then edit the formation of output 
information data can be exchanged and editing data information. QTVR primarily through static images to build three-dimensional and three-dimensional model, need the help of a graphic image acquisition devices, including digital cameras, fisheye, head, tripod and other common hardware [15]. Fisheye lens is a special external lens can be used to capture horizontal and vertical viewing angle of 180 degrees image, even at a distance of 1 meter or more, the depth of field of the imaging can reach infinity, for complex scenes only need to take two The pictures can complete imaging and broadcasting system. The head can rotate installed on a tripod and panoramic photography professional equipment, mainly to ensure that the fish-eye photo shoot, the camera nodes around the rotation node of the lens in the rotating shaft, eliminating the gap to ensure the success of the panoramic Flatten.

Capture videotaped machine VIDEO or S-VIDEO interface access the camera's video signal, commonly used to capture audio mixer commonly used LINE-IN port or microphone MIC-IN AUDIO-IN port For continuous dynamic video discredited into an image file you need to use the camera to shoot For generating a panoramic picture of the movie you need to take advantage of $3 \mathrm{D}$ software to generate. Production panoramic image or video data can be output through the VGA cable to the projector, with projector stunt projection; synthetic network will also be a good web format files online realtime, live and after-school-on-demand; You can also directly uploaded to the site with NV-SERVER courses editorial management; the you need transfer it by a method of carrier, the data can be also output by carving into a CD/DVD, QTVR virtual reality technology apply into practical teaching Recording System, see figure 2.

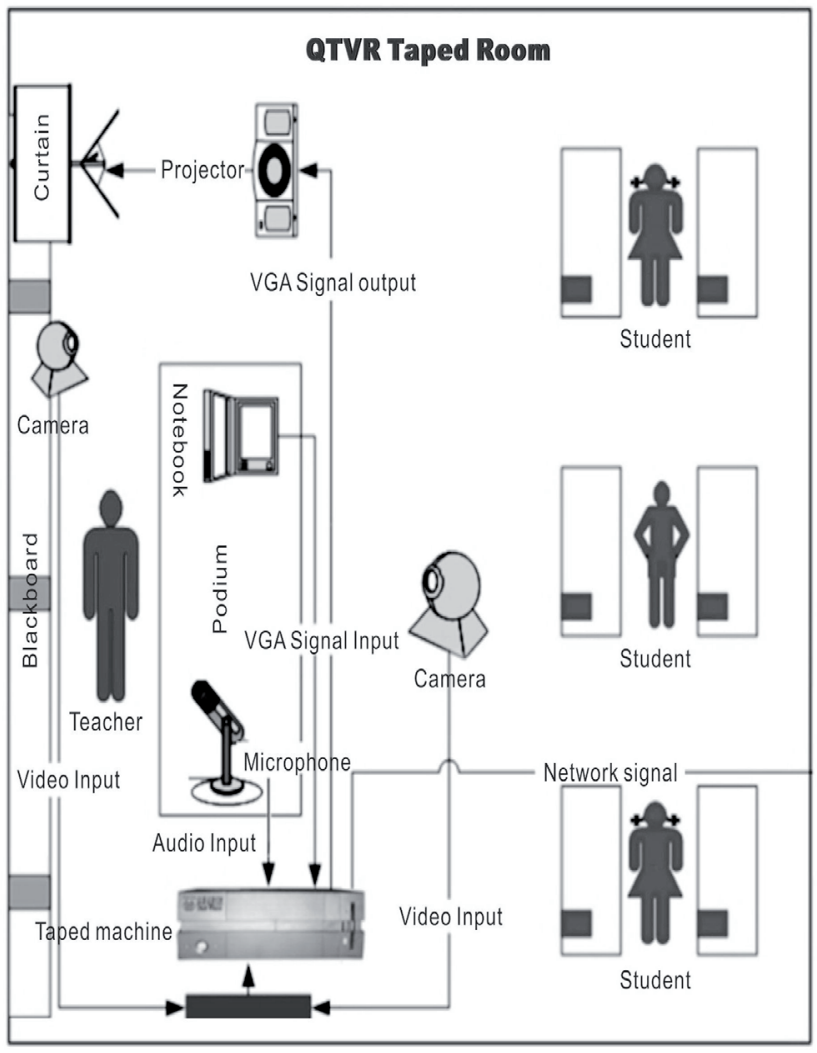

Figure 2. QTVR virtual reality technology apply into practical teaching Recording System
Based on the implement of QTVR virtual reality technology, videos, audios, computer images of teachers' tuition can be automatically integrated into documents of web format which can be automatically uploaded and requested by the students through the internet [16]. Teachers are able to organize various practical teaching materials efficiently, make web courseware selectively according to practical teaching materials, and finish the post-processing of the courseware easily, so that artificial duplication of efforts for lesson preparation and teaching can be replaced by web courses. By virtue of the QTVR virtual reality technology, it is easy to realize variety of functions of teaching including network broadcasting, timing recording of courses, electronic whiteboard, establishment of section index, management of course jurisdiction, automatic management of syllabus and edition and reorganization of courses [17].

Network broadcasting includes information such as figures, voice of teachers, multimedia presentation, sorts of electronic lecture notes, computer operation procedure, mouse track, blackboard-writing, animation, dynamic video, etc. Based on the webpage and online courseware, the information can be requested by the demote students and teachers who use the internet browsers; timing recording of courses includes tracking and positioning by QTVR virtual reality technology, and the system refers to the syllabus that was previously recorded and makes tracking shots for the teachers and students; electronic whiteboard function is that teachers write digital notes, mark key points with the built-in electronic pen, and the writing is synchronously recorded and the whole journey recording of teaching information is realized in no need of software installment and positioning; establishment of section index function means that via founding chapters, sections and paragraphs index for courses, realizes the quick jump and link between the index and contents, and given that multimedia carriers are compatible to courseware carriers of a variety of formats, it is not only limited in file format such as PPT, Word, Flash, EXE; management of course jurisdiction function can realize data management to course category and jurisdiction via setting up key words, administrator names, password and jurisdiction management; automatic management of syllabus function is that making ordered arrangement of practical teaching parameters such as names of the courses, places, classrooms, time and teachers according to teachers' and students' demands, and managing and maintaining each field and key word through database; edition and reorganization of courses function can edit, arrange, intelligently cut, and make any combination to the post-processing data of the courses, so that teachers are able to make adjustment to the teaching materials according to the teaching contents and teaching schedule. Besides the above, based on QTVR virtual reality technology, it is easy to realize functions and auxiliary study methods such as teaching material interlinking, stylized study notes, online interactive question and answer of students and teachers, projector effects, request, and online remote control.

\section{QTVR technology integration system of practical teaching}

The application of QTVR virtual reality technology to practical teaching recording does not need expensive equipments, and it only demands some basic equipments 
of audio and video collection. The operation can be completed by ordinary mouse and keyboard through scene control. The realization of QTVR virtual reality technology has pretty low demand for hardware equipments of practical teaching of colleges and universities. Its good compatibility makes it fit for mainstream operating systems including Windows XP, Windows7 and Mac OS. It also can operate in the crossplatform condition. The merits of QTVR virtual reality technology mentioned above lay sound foundation for its application to practical teaching recording [18].

Compared to traditional technology, QTVR uses panoramas of real world to build up virtual reality, and its image quality and virtual construction are more vivid than images which are produced by computer. It is feasible to get film of different effects and scenes by the adjustment of lens and filters. Its higher quality of clarity, more comprehensive images, and more vivid details are unparalleled to the 3D simulation of ordinary computer. Meanwhile, QTVR virtual reality technology offers perspectives of observing-scene, which enable users to get both immersive experience of looking around and chance to observe real objects from different angles of the scene, which uplift the VR experience of the participating users to the maximum degree. Due to adopt the particular patent of compress technique of Apple Inc, QTVR can compress a panoramic image of 360 degrees to an image that is less than $540 \mathrm{~K}$. Compared with traditional technique, QTVR has a smaller volume of data. This difference on the order of magnitude makes QTVR film store more images with the disk space of same size when compared with other virtual reality technology [19]. In the same scene, users' operation is more convenient, and with the same information storage capacity, QTVR virtual reality technology can contain more data information. Therefore, it can save more resources and time costs at the sections of digital shooting node making, scene making, and promote the controllability of recording system fabrication [20].

The practical teaching recording system that is based on QTVR virtual reality technology can make seamless data integration with various current network teaching platform, constitute complete teaching resource accumulation and resource utilization. For the resource users which are usually colleges and universities, it enables them to alleviate financial pressure for repeat purchase of equipments to the maximum degree, and play full use of current hardware equipments. Teachers and students just need to access the network to see the live teaching or request the teaching records. There are no limitations of user node number, and it realizes inter-network receiving of different band width of both broadband and narrowband. The video can be played fluently in different types of network such as local area network, metropolitan area network, and wide area network. The practical teaching recording system that is based on QTVR virtual reality technology can offer students excellent resources of the course library according to students' learning progress. Students can learn on own condition. It also offers teachers excellent resources of the course library to enable them learn advanced teaching thought and model from excellent teachers. Depending on the utilization of the practical teaching recording system, coefficient of utilization of school network and network resources is fully uplifted, and practical teaching quality is promoted.

\section{CONCLUSIONS}

There is a most important process in practical teaching process. It is presenting knowledge information. QTVR virtual reality technology gains virtual reality experience at a certain degree with extremely low cost; presents knowledge information of practical teaching with unique methods; overcomes the disadvantages of the current practical teaching courses that is a lack of firsthand participation; accelerates and consolidates students' process of knowledge study through offering real VR experiences in a vast realm of practical teaching subjects.

By dint of that QTVR virtual reality technology does not need any special hardware and auxiliary instrument, and can give full play to the constitution of dimensional space, dimensional objects and virtual space, and can be applied to exhibit introduction and virtual scene construction, and can make seamless connection with other practical teaching information system and save hardware cost to maximum degree. The research for QTVR virtual reality technology will inevitably promote the transmission and application of virtual reality technology.

\section{ACKNOWLEDGMENT}

This work is supported by the Humanity and Social Science Youth foundation of Ministry of Education (No. 13YJC880133), Chongqing Education Committee educational reform project (No.1202096), Chongqing science of education plan and the Research Foundation of Chongqing University of Education (No.JG201234).

\section{REFERENCES}

[1] Rajesh K. Maurya, Computer Graphics with Virtual Reality Systems, India: Wiley, 2009.

[2] Grigore C. Burdea and Philippe Coiffet, Virtual Reality Technology, 2nd ed. Delhi: Wiley, 2008.

[3] Michael Anissimov, "What is Virtual Reality? ", wiseGEEK. [Online]. Available: http://www.wisegeek.com/what-is-virtualreality.htm. [Accessed: Janu. 16, 2013].

[4] Ankit, P., Ajinkya, P., Pratik, M., Piyush, M. "Secure Authentication using Anti-Screenshot Virtual Keyboard", International Journal of Computer Science Issues, vol. 8, no 3, 2011, pp. 534-537.

[5] S. J. Russell, P. Norvig, Artificial Intelligence: A Modern Approach, San Antonio: Pearson Education, 2009.

[6] Kenneth W. Michael Wills, "What Are the Different Types of Virtual Reality Technology?", wiseGEEK. [Online]. Available: http://www.wisegeek.com/what-are-the-different-types-of-virtualreality-technology.htm. [Accessed: Janu. 10, 2013].

[7] Huiqin Zhao, Bo Sun, "Research of Virtual Teacher with Emotional Support Based on Virtual Agent Technology", China Educational Technology, vol.11, 2010, pp.117-123.

[8] Marc Bernatchez, "Applications in Virtual reality", Virtual Reality Resources, Dec. 21, 2004. [Online]. Available: http://vresources.org/applications/applications.shtml. [Accessed: Janu. 14, 2013].

[9] Bricken, M., "Virtual Reality Learning Environments: Potentials and Challenges", Computer Graphics, vol. 25, no. 3, 1991. http://dx.doi.org/10.1145/126640.126657

[10] Donovan, P., "Virtual reality and children's spirituality", Stimulus, vol. 18 , No. 4, 2010.

[11] D. May, C. Terkowsky, T. Haertel, and C. Pleul, "Using EPortfolios to support experiential learning and open the use of teleoperated laboratories for mobile devices," in REV2012 Remote Engineering \& Virtual Instrumentation, Bilbao, Spain, Conference Proceedings, M.E. Auer and J. García Zubía, Eds. IEEE, 2012, pp. 172-180.

[12] Reinhard, K., "The German Berufsakademie Work-Integrated Learning Program: A Potential Higher Education Model for West 
PAPER

Research on Practical Teaching Recording System BASED on QuickTime ViRTual Reality TeChNOLOGy

and East", Asia-Pacific Journal of Cooperative Education, vol. 7, no.1, 2006, pp. 16-21.

[13] Orrell, J., "Work-integrated Learning Programmers: Management and Educational Quality", Proceedings of the Australian Universities Quality Forum, AUQA Occasional Publication, 2004

[14] Skylar, A.A. , "Assistive technology online resources", Journal of Special Education Technology, vol.21, no.1, 2006, pp. 45-47.

[15] Smith, J.E., Meijer, G., Kielly-Coleman, N., "Assurance of learning: the role of work integrated learning and industry partners, In Campbell, M.Ed., Work Integrated Learning: Responding to Challenges", Australian Collaborative Education Network (ACEN)Incorporated, Curtin University of Technology, Perth, WA, 2010, pp.409-419.

[1] [16] Wyld, D.C., "A Second Life for organizations? managing in the new, virtual world", Management Research Review, vol. 33, no. 6, 2010, pp. 529-562. http://dx.doi.org/10.1108/ 01409171011050181

[17] Waleed, A. S. "Work Integrated Learning (WIL) In Virtual Reality (VR)" International Journal of Computer Science Issues, vol. 9, no 2, 2012, pp. 332-344

[18] Lepouras, G., Katifori, C., Vassilakis A, Charitos D., "Real exhibitions in a virtual museum", Virtual Reality, vol.7, 2004, pp. 120-128. http://dx.doi.org/10.1007/s10055-004-0121-5

[19] Stoyan, M., Dimo, C., "Affordable Virtual Reality System Architecture for Representation of Implicit Object Properties",
International Journal of Computer Science Issues, vol. 9, no 2, 2012, pp. 23-29

[20] Qilong Cheng, Ping Tang, Shuping Zhang, "Research on Virtual Modeling Method Based on Agent-oriented", Journal of Guangdong University of Technology, vol.25, no.2, 2008, pp.62-65.

\section{AUTHORS}

Y. Y ZHU received her B.S. degree in Computer Science from Southwest Agricultural University, and he M.S. degree in educational technology from Southwestern University, in 2003 and 2009, respectively. He is currently working towards a Ph.D.at Southwest University of Political Science and Law. Since 2011 he has been working as Associate Professor at the Department of Economics and Business Administration of Chongqing University of Education, Chongqing, People's Republic of China (zhuyongyong@126.com).

Submitted, March, 19, 2013. Published as resubmitted by the authors on November, 16, 2013. 